\title{
Sativa seeds against Schistosoma mansoni different stages
}

\section{Azza M Mohamed/+ Nadia M Metwally, Sohair S Mahmoud*}

\author{
Department of Medicinal Chemistry, National Research Centre, Dokki, Egypt *Department of Parasitology, Theodor Bilharz \\ Research Institute, Giza, Egypt
}

The schistosomicidal properties of Nigella sativa seeds were tested in vitro against Schistosoma mansoni miracidia, cercariae, and adult worms. Results indicate its strong biocidal effects against all stages of the parasite and also showed an inhibitory effect on egg-laying of adult female worms. In the present work we also studied the effects of crushed seeds on some antioxidant enzymes; which have a role in protection of adult worms against host oxidant killing; as well as some enzymes of glucose metabolism; which have a crucial role in the survival of adult worms inside their hosts. The data revealed that the used drug induce an oxidative stress against adult worms which indicated by a decrease in the activities of both antioxidant enzymes, superoxide dismutase, glutathione peroxidase, and glutathione reductase and enzymes of glucose metabolism, hexokinase and glucose-6-phosphate dehydrogenase. Disturbing of such enzymes of adult worms using N. sativa seeds could in turn render the parasite vulnerable to damage by the host and may play a role in the antischistosomal potency of the used drug.

Key words: Nigella sativa - Schistosoma mansoni - miracidia - cercariae - adult worms - antioxidant enzymes glucose metabolism

Trematode worms of the genus Schistosoma cause the disease schistosomiasis in man and animals. The first stage of Schistosoma mansoni is the miracidia which live inside their intermediate host Biomphalaria alexandrina snails. Inside the snail, the miracidia are transformed into mother sporocysts which develop into daughter sporocysts and these in turn give rise to the mature cercariae. Infection is caused by cercariae which penetrate the skin of the final host. The head of the cercariae is transformed into an endoparasitic larva, the schistosomula (Hussein et al. 1976). Adult S. mansoni in the mesentric vein are resistant to the host immune response which at the same time is capable of overcoming further infection by cercariae (Smithers \& Terry 1969, James 1992). The major component of the immune response is cell mediated and as part of that response, the parasite is exposed to reactive oxygen species (ROS) generated by the host effector cells as macrophages, eosinophils, neutrophils , and platelets (Callahan et al. 1988, Maizels et al. 1993, James 1994). To defend themselves against oxygen-mediated killing mechanisms of host, parasites have developed antioxidant enzyme systems. In S. mansoni superoxide dismutase, SOD, glutathione peroxidase, GPX, glutathione reductase, GR, and glutathione-s-transferase, GST, are major antioxidant enzymes that are involved in detoxification processes (Callahan et al. 1988, Mkoji et al. 1988 a,b, Nare et al. 1990, O’Leary \& Tracy 1991, O'Leary et al. 1992, James 1994, Mei \& LoVerde 1995). These schistosome oxidant-detoxicating systems play a role in protecting the parasite from damage as a result of ROS (Callahan et al. 1988 a,b, Brophy \& Pritchard 1992, James 1994). Therefore, the antioxidant defence mechanisms of adult worms may represent po-

\footnotetext{
${ }^{+}$Corresponding author. E-mail: Azzanrc @ hotmail.com. Received 11 January 2004 Accepted January 2005
}

tentially good target for chemotherapy. On the other hand, adult schistosomes by virtue of an incomplete citric acid cycle, are nearly totally dependant on anaerobic glycolysis for their energy requirement. They utilize $1 / 5$ of its dry weight of glucose/hour converting $80 \%$ to lactic acid, so glycolytic pathway may also represent additional site for selective chemotherapeutic intervention (El-Kouni 1992).

There are limited options vailable for the chemotherapeutic treatment of schistosoma infection with the drug of choice being praziquantel (WHO 1993, 1999). Unfortunately, the long-term world wide application of the drug coupled with the recent discovery of praziquantel-tolerant schistosomes has generated concern over the development of drug-resistant schistosoma strains (Shengliang et al. 2001, Appiah \& DeVlas 2002). So for combating schistosomiasis there is an urgent need to develop new drug alternative to praziquantel. Traditional medicinal plants were applied by some authors for the treatment of schistosomiasis (Ndamba et al. 1994, Sparg et al. 2000, Molgaard et al. 2001).

N. sativa L. (Family: Ranunculacea), commonly known as black seed, black cumin or habatul Barakah, is an erect herbaceous annual plant. It grows in Mediterranean countries and it is one of the native plants that are widely distributed in Egypt (Jansen 1981). For thousands of years, the seeds have been used for medical purpose. Pharmacological investigations suggest that the black seed oil exhibited hepatoprotective effect against liver damage (AlGharably et al. 1997, Nagi et al. 1999). Besides, the essential oil was shown to have anthelmentic activity (Agarwal et al. 1979) and the seeds were effective against cestodes and nematodes (Akhtar \& Rifaat 1991). In view of these findings, this study was undertaken to evaluate, in vitro, the antischistosomal effect of $N$. sativa crushed seeds against $S$. mansoni miracidiae, cercariae (free living stages), and adult worms. Also the study was extended to investigate the potential role of the black seeds against some antioxidant protecting enzymes (SOD, GPX, and GR), 
which play a crucial role in the survival of adult worms inside the host, as well as some enzymes of glucose metabolism (HK and G-6-PDH) as two different sites that may represent good targets for chemotherapy.

\section{MATERIALS AND METHODS}

Chemicals - Chemicals were of analar quality, products of Merck, Germany and Sigma, US.

The parasite - S. mansoni NMRI strain was used. (1) Miracidia: schistosome eggs and miracidia were obtained from livers of experimentally infected mice according to the method described by Hira and Webbe (1972) and used directly in the bioassays; (2) Cercariae: S. mansoni cercariae were obtained from experimentally infected snails by exposing them to artificial $28^{\circ} \mathrm{C}$ where the released cercariae were used directly after shedding (Pellegrino \& De Maria 1966). Snails were obtained from Schistosomiasis Biological Supply Program, SBSP, Theodor Bilharz Research Institute, Imbaba, Giza; (3) Adult worms: 10 male hamsters (Mesocricetus auratus) provided by a laboratory-bred colony of similar age and mass (100-140 g) were obtained from SBSP. Each hamster was exposed separately to $150 \mathrm{~S}$. mansoni cercariae for $1 \mathrm{~h}$ using the partial immersion technique (Oliver \& Stirewatt 1952). After 8 weeks post-infection (PI) adult worms were recovered from hepatic portal system and liver by the perfusion technique previously described by Smithers and Terry (1963).

Efficacy of N. sativa crushed seeds on different stages of S. mansoni parasite - (1) The miracidia: miracidia tests were carried out using the technique described by Techounwou et al. (1991). Laboratory tissue culture plates were used as test chambers to observe the viability and death of miracidia under the dissecting microscope; 20 miracidia were placed in $1 \mathrm{ml}$ dechlorinated water in each well of the test chamber. Serial double concentrations (0.5$5 \mathrm{ppm}$ ) of $N$. sativa crushed seeds (which dissolved in dimethylsulfoxide DMSO) were then added giving a total of $2 \mathrm{ml}$ in each experimental well. Three replicates were made for each tested concentration. Mortality of miracidia was recorded after one min. Twenty freshly hatched miracidia were maintained in $2 \mathrm{ml}$ dechlorinated water as controls; (2) The cercariae: series of $1 \mathrm{ml}$ samples of water containing 20 freshly shed cercariae were mixed with $1 \mathrm{ml}$ of a double serial concentrations ( $0.5-5 \mathrm{ppm})$ of $N$. sativa crushed seeds dissolved in DMSO. Three replicates were made for each tested concentration. Viability of the cercariae was determined by removing the tested material after $5 \mathrm{~min}$ of exposure period and replacing it with fresh water for a recovery period of $24 \mathrm{~h}$. Two $\mathrm{ml}$ dechlorinated water containing 20 freshly shed cercariae were used as control, according to Ritchie et al. (1974); (3) S. mansoni adult worms: male, female and coupled adult worms, each of 20 worms, were cultured in 24 well Falcon plates at $37^{\circ} \mathrm{C}$ in $1 \mathrm{ml}$ of RPMI-1640 media supplemented with penicilin $(100 \mathrm{U} / \mathrm{ml})$, streptomycin $(100 \mathrm{mg} / \mathrm{ml})$, and $10 \%$ fetal calfserum (Gibco), $2 \mathrm{~g} / \mathrm{l}$ glucose, $0.39 \mathrm{~g} / \mathrm{l}$ glutamate, and 20 $\mathrm{g} / 1 \mathrm{NaHCo}_{3}$. N. sativa crushed seeds were dissolved in $10 \%$ DMSO and then diluted with sterilized distilled water to the desired concentrations (range from 10-110 ppm).
Control worms were treated with $10 \%$ DMSO in sterile distilled water. The movement and viability of the adult worms were monitored for $24 \mathrm{~h}$. All procedures were carried out using aseptic techniques in a laminar flow cabinet (John Bass Ltd.). The media were removed and replaced with fresh media without the tested material and recovery of the adult worms was monitored for another 48 h. Egg production by female adult worms which survival the exposure was measured daily by manual counting under an inverted microscope (Leitz, Diavert); (4) Preparation of parasite homogenates: male and female $S$. mansoni adult worms were separated and maintained in an ice-bath at $4^{\circ} \mathrm{C} ; 0.1 \mathrm{~g}$ of both male and female worms were separately homogenized in ice cold bidistilled water to yield $10 \%$ homogenate using a glass homogenizer. The homogenate were centrifuged at 4000 r.p.m. and the supernatants were collected and used for enzyme assays. The protein concentration was determined by the method of Bradford (1976) with bovine serum albumin as a standard.

Enzyme assay - (1) Glutathione peroxidase (GPX): the enzyme was determined by the method of Paglia and Valentine (1967) using NADPH-coupled reduction of GSSG, catalysed by $\mathrm{GR} . \mathrm{H}_{2} \mathrm{O}_{2}$ was used as substrate. Oxidation of NADPH was followed at $340 \mathrm{~nm}$ and one unit of enzyme activity is defined as the oxidation of 1 nmole NADPH/min/mg protein; (2) Glutathione reductase (GR): GR was assayed by the method of Goldbery and Spooner (1983). The reaction mixture contained $120 \mathrm{mM}$ potassium phosphate buffer, pH 7.2, 15 mM EDTA, 63 mM GSSG and $9.6 \mathrm{mM}$ NADPH. The oxidation of NADPH was followed at $340 \mathrm{~nm}$ and one unit of activity is defined as the oxidation of $1 \mathrm{nmole}$ NADPH/min/mg protein; (3) Superoxide dismutase (SOD): SOD activity was determined by monitoring the decrease in absorbance due to NADH oxidation at $340 \mathrm{~nm}$ using the method of Paoletti et al. (1986). Enzyme activity is expressed as nmole NADH oxidized/ min/mg protein; (4) Hexokinase (HK): glucose-6-phosphate formed by HK reaction is measured by adding glucose-6- phosphate dehydrogenase and NADP, then NADPH formation was followed at $340 \mathrm{~nm}$ (Uyeda \& Racker 1965). Enzyme activity is experessed as nmole NADPH formed/min/mg protein; (5) Glucose-6-phosphate dehydrogenase (G-6-PDH): the enzyme activity was assayed in a reaction mixture contained triethanolamine buffer ( $86 \mathrm{mM}$, pH 7.6), $\mathrm{MgCl}_{2}(6.9 \mathrm{mM})$, glucose-6-phosphate $(1 \mathrm{mM})$, NADP $(0.39 \mathrm{mM})$. The reduction of NADP was followed at $340 \mathrm{~nm}$ and one unit of activity is defined as the reduction of $1 \mathrm{nmole} \mathrm{NADP} / \mathrm{min} / \mathrm{mg}$ protein (Bergmeyer et al. 1974).

Statistical analysis - Data were computed by comparing values for treatment groups with the values for individual control. Results from independent observations were expressed as mean \pm S.D. The significance among values were analyzed using t-test.

\section{RESULTS}

The viability of $S$. mansoni different stages (miracidia, cercariae, and adult worms) was observed during the in 
vitro incubation with various concentrations of $N$. sativa crushed seeds.

Fig. 1 shows that the exposure of miracidia and cercariae to the drug resulted in the death of the parasite and this lethal effect was dependent on the concentration and time of the incubation (after $1 \mathrm{~min}$ for miracidia and $5 \mathrm{~min}$ for cercariae). $\mathrm{LC}_{50}$ values of this drug were $1 \mathrm{ppm}$ and 2 ppm for miracidia and cercariae respectively.

Fig. 2 shows the effect of the current drug on mortality rates of male and female adult worms after $24 \mathrm{~h}$. It was observed that the drug have a strong lethal effect against both male and female worms showing an $\mathrm{LC}_{50}$ of 40 and 60 ppm respectively; $100 \%$ of the parasite were dead at concentration of $100 \mathrm{ppm}$ for male worms and $110 \mathrm{ppm}$ for female worms. Coupled worms become separated into male and female worms under the effect of the drug, however, the control untreated paired worms remain coupled throughout the observation period and exhibited vigorous activity.

The effect of $N$. sativa crushed seeds on daily egg production by adult female worms was not observed as the result of the separation of adult worm pairs, but control worm pairs showed an increase in egg-production from 11-15 eggs in the first day to 35-43 eggs/ adult female worm/day on second and third day.

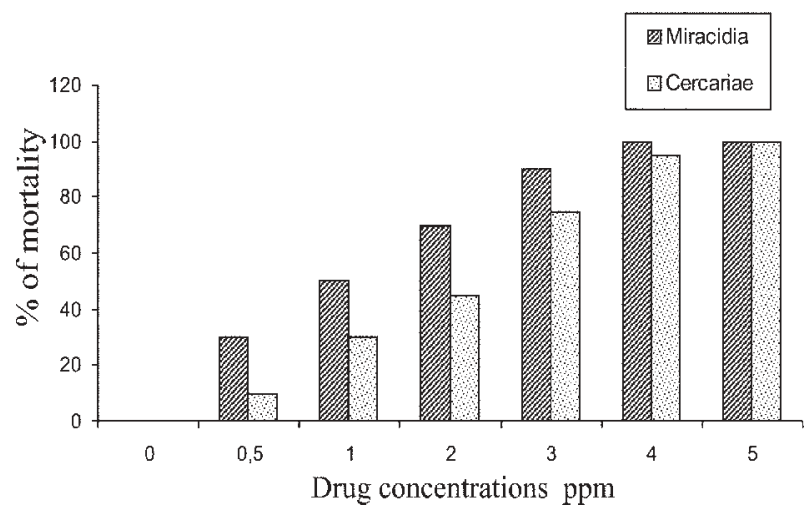

Fig. 1: effect of Nigella sativa crushed seeds on mortality rate of Schistosoma mansoni miracidia and cercariae after 1 and 5 min of exposure respectively.

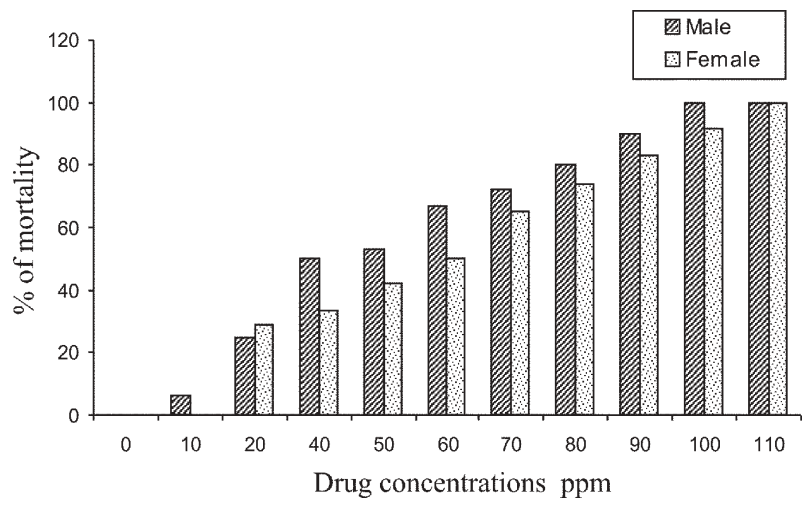

Fig. 2: effect of Nigella sativa crushed seeds on mortality rate of male and female Schistosoma mansoni adult worms after $24 \mathrm{~h}$ of exposure.

Results listed in the Table show the effect of $N$. sativa on some antioxidant enzymes (SOD, GR, and GPX) and enzymes of glucose metabolism (HK and G-6-PDH) of both male and female adult worms using $\mathrm{LC}_{50}$ for male $(40 \mathrm{ppm})$ and female $(60 \mathrm{ppm})$. The data confirm that there was a significant inhibition of these enzymes in both male and female worms under the effect of the current drug. The inhibition was consistently higher in males than in female worms.

\section{DISCUSSION}

This study was performed to evaluate in vitro the antischistosomal effect of $N$. sativa crushed seeds (black seed) for controlling schistosomiasis. In the last decades, plant extracts were widely used for the treatment of schistosoma infection (Sparg et al. 2000, Molgaard et al. 2001). However, $N$. sativa seeds oil was recently found to have anthelmintic activity against $S$. mansoni infection (Mahmoud et al. 2002).

The current study demonstrated that $N$. sativa crushed seeds possesses strong schistosomicidal activity against S. mansoni miracidia, cercariae, and adult worms (female and male worms).

These results are in harmony with Mansour et al. (2002) who revealed the miracidal and cercaricidal potency of

TABLE

Effect of Nigella sativa crushed seeds on some antioxidant enzymes and enzymes of glucose metabolism in tissue homogenates of Schistosoma mansoni female and male adult worms using $\mathrm{LC}_{50}$

\begin{tabular}{|c|c|c|c|c|}
\hline \multirow[b]{2}{*}{ Enzyme $^{a}$} & \multicolumn{2}{|c|}{ Female worms } & \multicolumn{2}{|c|}{ Male worms } \\
\hline & Control & Treated & Control & Treated \\
\hline Superoxide dismutase & $8.22 \pm 1.339$ & $4.26 \pm 0.609^{c}$ & $6.76 \pm 0.73$ & $2.13 \pm 0.48^{c}$ \\
\hline Glutathione reductase & $32.27 \pm 5.175$ & $11.63 \pm 1.20^{c}$ & $29.83 \pm 6.69$ & $5.48 \pm 0.73^{c}$ \\
\hline Glutathione peroxidase & $72.82 \pm 15.22$ & $48.70 \pm 1.887^{b}$ & $69.16 \pm 12.78$ & $46.27 \pm 5.479^{b}$ \\
\hline Hexokinase & $110.81 \pm 6.088$ & $54.79 \pm 8.158^{b}$ & $84.93 \pm 5.78$ & $42.00 \pm 5.479^{b}$ \\
\hline $\begin{array}{l}\text { Glucose-6-phosphate } \\
\text { dehydrogenase }\end{array}$ & $57.83 \pm 4.32$ & $40.79 \pm 2.37^{b}$ & $43.22 \pm 3.23$ & $18.63 \pm 1.217^{b}$ \\
\hline
\end{tabular}

$a$ : data are presented as mean \pm S.D; results are the average of five determinations; $b$ : significant change as compared to control (P < $0.01) ; c$ : significant change as compared to control $(\mathrm{P}<0.001)$. 
the black seed at different extracts (petroleum ether, chloroform, ethanol, and water). Also, Mahmoud et al. (2002) stated that administration of the black seed oil to $S$. mansoni infected mice showed high activity against adult worms. In addition, similar results have been recorded on the effect of other plants against schistosome at different stages cercariae, schistosomula and adult worms (Naples et al. 1992, Ahmed \& Ramzy 1997, Molgaard et al. 2001, Lyddiard et al. 2002).

The present investigation indicated that different concentrations (10-100 ppm) of crushed seeds were highly effective in inhibiting egg-laying by adult female worms after $24 \mathrm{~h}$ of exposure in comparison to control untreated female worms. This may be due to separation of adult worm pairs under the effect of the used drug indicating that this drug affects the ability of both male and female worms to couple and consequently inhibit egg output by female adult worms.

This data was supported by Mahmoud et al. (2002) who declared that treatment of mice infected with $S$. mansoni parasite, by using black seed oil, was effective in reducing egg count in both liver and intestine. Also, goyazensolide, a natural compound isolated from the plant Eremanthus goyazensis, showed a significant inhibitory effect on egg laying of $S$. mansoni female worms during in vitro cultivation (Barth et al. 1997).

The present work was extended to study the effect of the crushed seeds on some antioxidant enzymes (SOD, GR, and GPX) as well as some enzymes of glucose metabolism (HK and G-6-PDH) of adult female and male worms aiming to explain the possible mechanism of its action against $S$. mansoni parasite.

The levels of the antioxidant enzymes, SOD, GR, and GPX were determined in the tissue homogenates of normal untreated female and male worms. The results demonstrated that GPX is the most abundant enzyme, indicating that GPX is the major tegumental antioxidant enzyme. This result is consistent with previous data, suggesting that GPX might be a pivotal enzyme in the protection of schistosome adult worms against host oxidant Killing (Mkoji et al. 1988b, Smith et al. 1989, Mei et al. 1996). Generally previous studies have shown that the adult worm, which is the least susceptible to host immune attack, showed the highest level of antioxidant enzymes, while the most susceptible larval stages showed the lowest level of expression (Mei \& LoVerde 1997).

For antioxidant enzymes to play a crucial role in the survival of adult worms in the host, they need to be located at the host-parasite interface where the host cellular response including degranulation and the release of ROS. In adult schistosome, the antioxidant scavengers are concentrated in the tegument and gut epithelium (Mei $\&$ LoVerde 1997). Localization of antioxidant enzymes in the tegument might be an adaptive response of the adult schistosomes to protect themselves against the host cellular response. In the gut epithelium, this could be because the intestinal lumen is filled with host blood cells, which might create an environment for release of ROS. However, the most obvious effect of host ROS on the schistosome, is at the parasite's surface (Hong et al. 1992 Mei et al. 1996). The worm tegument is composed of a heptalaminar membrane of two lipid bilayers (Mclaren 1980). Outer bilayer is rich in phospholipids and sterols (Caulfield et al. 1991). During infection, it is likely that membrane phospholipids are continually subjected to host oxidant challenges, initiating process of lipid peroxidation that results in the formation of lipid and phospholipid hydroperoxides, which decompose further to toxic carbonyl species, so the peroxidized membranes become rigid, lose selective permeability and their integrity (LoVerde 1998). So it was suggested that in schistosomes, the first line of enzymatic cellular defense against hydroperoxidation involves SOD, GPX, and GR which are associated with adult worm tegument (Mei et al. 1996 Mei \& Lo Verde 1997).

Concerning with the effect of $24 \mathrm{~h}$ exposure of female and male adult worms to the crushed seeds, using $\mathrm{LC}_{50}$ for female $(60 \mathrm{ppm})$ and $\mathrm{LC}_{50}$ for male $(40 \mathrm{ppm})$, on the antioxidant enzymes, SOD, GR, and GPX in tissue extracts of both sexes, which survive the exposure, the results revealed that the used drug severely reduced these enzymes in comparison to normal untreated worms, indicating that the schistosomicidal effect of the crushed seeds was directed against the antixoidant enzyme system of the adult worms, which play a role in protecting the parasite from the effect of resulting ROS produced by the host effector cells (Callahan et al. 1988, Brophy \& Pichard 1992, Hong et al. 1992, Mei et al. 1996, Roche et al. 1996).

The same effect was obtained by some synthetic schistosomicidal drugs against parasite antioxidant enzymes (Mkoji et al. 1989, Nare et al. 1991, Xiao et al. 2002). The authors suggested that the inhibition of such enzymes in adult worms could lead to increased schistosome susceptibility to host oxidant attacking and might be linked with antischistosomal action of these drugs.

The reduction in antioxidant enzymes of treated worms may be due to oxidative stress which is used to describe a state of damage caused by elevated oxygen free radicals which may exceed the capability of these enzymes as they are used as free radicals scavengers (Kalra et al. 1994). In addition, Sharma and Agarwal (1996) stated that cellular damage arises when the equilibrium between the amount of ROS produced and that of scavenged antioxidants is disturbed. This data suggested that the used drug may lead to the impairment of ROS catabolizing system of the parasite, and such process is may be closely related to the killing of the parasite. Impairment of the antioxidant enzymes of crushed seed-treated worms may indicate that the tegument as well as the gut epithelium are two sites attacked by the drug (Mei \& LoVerde 1997).

It seems likely that the tegumental changes in the worms may be an important aspect of drug activity leading to the death and elimination of worms with stopping of their egg production (Nosseir et al. 2000). Drug-induced tegumental changes has been described in S. mansoni worms after treatment with a variety of schistosomicidal drugs (Otubanjo 1981, Moczon \& Swidersk 1983).

Our study was extended to evaluate the biocidal effect of $N$. sativa crushed seeds on HK and G-6-PDH enzymes in tissue homogenates of adult female and male $S$. mansoni worms, as two different pathways of glucose metabolism. HK is the first rate limiting enzyme in glyco- 
lytic bioenergetic pathway, catalyzes the phosphorylation of glucose to glucose-6-phosphate while G-6-PDH is the first enzyme in pentose phosphate pathway (an alternative pathway for glucose oxidation in which no ATP is generated), catalyzes the oxidative conversion of G-6phosphate to ribose-5-phosphate with the generation of NADPH which is needed for the maintenance of glutathione in its reduced form.

In the current work, the activity of HK in normal untreated healthy worms is about twice the level of G-6$\mathrm{PDH}$. These data indicated the high utilization of glycolysis by adult schistosomes as main source of energy (Coles 1973, El-Kouni 1992). Also, Mansour et al. (2000) stated that $S$. mansoni depends on glycolysis for its survival inside their hosts.

The in vitro treatment of adult $S$. mansoni worms (male and female) with $N$. sativa crushed seeds using $\mathrm{LC}_{50}$, significantly inhibited tissue $\mathrm{HK}$ and G-6-PDH activities in relation to normal untreated worms. This may give a clue that both glycolytic and phosphate pentose pathways are other two sites attacked by the used drug. These results are in accordance with those obtained by some authors, using synthetic drugs, suggesting that the decrease in these enzyme activities might reflect the alteration occurring during the parasite damage induced by the drugs (Moczon \& Swidersk 1983, Tielens et al. 1985, Xiao et al. 1998 a, b, 2000).

Inhibition of HK in adult schistosomes by the used drug presented in the current study, may inhibit glucose breakdown which is nearly the main source of energy for their survival, in addition, the loss of HK activity is considered to be one of the first signals of cellular damage leading to any gross tissue damage (Stocchi et al. 1994). On the other hand, inhibition of G-6-PDH activity may reduce the capacity of the cell to protect itself from the oxidative stress because less amount of NADPH is produced. Lower NADPH concentration may impair the parasite's capacity to generate reduced glutathione (GSH), which protect cell membrane and other cellular structure from oxidation (Mckee \& Mckee 1999).

It could be concluded that the use of $N$. sativa seeds as antischistosomal drug may affect the adaptive capability of adult worms against the oxidative killing by the host effector cells and this may help in the elimination of the parasite.

\section{REFERENCES}

Agarwal R, Kharya MD, Shrivastava R 1979. Antimicrobial and anthelminitic activities of the essential oil of Nigella sativa. Linn. Indian J Exp Biol 17: 1264-1265.

Ahmed AH, Ramzy RMR 1997. Laboratory assessment of the molluscicidal and cecaricidal activities of the Egyptian weed, Solanum nigrum L. Ann Trop Med Parasitol 91: 931-937.

Akhtar MS, Rifaat S 1991. Field trial of Saussurea lappa roots against nematods and Nigella sativa seeds against cestodes in children. J Pakistan Med Ass 41: 185-187.

Al-Gharably NM, Badary OA, Nagi MN, Al-Sawaf HA, AlRikabi AC, Al-Bekairi AM 1997. Protective effect of thymoquinone against carbon tetrachloride-induced hepatotoxicity in mice. Res Comm Pharmacol Toxicol 2: 41-50.
Appiah AD, DeVlas SJ 2002. Interpreting low praziquantel cure rates of Schistosoma mansoni infections in Senegal. Trends Parasitol 18: 125-129.

Barth LR, Fernandes APM, Riberio-Paes JT, Rodrigues V 1997. Effects of goyazensolide during in vitro cultivation of Schistosoma mansoni. Mem Inst Oswaldo Cruz 92: 427-429.

Bergmeyer HU, Bernt E, Grassl M, Michel G 1974. Glucose-6phosphate dehydrogenase. In UH Bergmeyer, Methods of Enzymatic Analysis, Verlag Chemie Weinheim, Academic Press, New York, p. 458-459.

Bradford MM 1976. A rapid and sensitive method for the quantitation of microgram quantities of protein utilizing the principle of protein-dye binding. Anal Biochem 72: 248-254.

Brophy PM, Prichard DI 1992. Immunity to helminthes: Ready to tip the biochemical balance? Parasitol Today 8: 419-422.

Callahan HL, Crouch RK, James ER 1988. Helminth antioxidant enzymes: A protective mechanism against host oxidants? Parasitol Today 4: 218-225.

Caulfield JP, Chiang CP, Yacona PW, Smith LA, Golaw DE 1991. Low density lipoproteins bound to Schistosoma mansoni do not alter the lateral diffusion or shedding of lipids in the outer surface membrane. J Cell Sci 99: 167173.

Coles GC 1973. The metabolism of schistosome A review. Int J Biochem 4: 319-337.

El Kouni MH 1992. Chemotheraphy of schistosomiasis. Rhode Island Med 75: 212-216.

Goldberg DM, Spooner RJ 1983. Glutathione reductase. In U $\mathrm{H}$ Bergmeryer, Methods in Enzymatic Analysis, Verlag Chemie Weinheim Academic Press, New York, p. 258-265.

Hira PR, Webbe J 1972. The effect of sublethal concentrations of the molluscicide triphenyl lead acetate on Biomphalaria glabrata and on the development of Schistosoma mansoni in the snail. Helminthololgy 45: 11.

Hong Z, Kosman D, Thakur A, Rekosh D, Lo Verde PT 1992. Identification and purification of a second form of $\mathrm{Cu} / \mathrm{Zn}$ superoxide dismutase from Schistosoma mansoni. Infect Immun 60: 3641-3651.

Hussein MF, Kasem EA, Abdel Wahab A, Hamdi AR, Bishai HM, Mahmoud MF 1976. Principles of Animal Biology, Dar El-Marref, Cairo.

Jansen PCM 1981. Spices, Condiments and Medicinal Plants in Ethiopia, their Taxonomy and Agricultural Significance, Center for Agricultural Publishing and Documentation, Addis Ababa, p. 76-85.

James ER 1994. Superoxide dismutase. Parasitol Today 10: 481-484.

James SL 1992. Experimental models of immunization against schistosomes: lessons for vaccine development. Immun Invest 21: 477-493.

Kalra J, Mantha SV, Prasad K 1994. Oxygen free radicals: key factors in clinical diseases: Lab Med Int XI: 16.

LoVerde PT 1998. Do antioxidants play a role in schistosome host-parasite interactions? Parasitol Today 14: 284-289.

Lyddiard JR, Whitfield PJ, Bartlett A 2002. Antischistosomal bioactivity of isoflavonoids from Millettia thonningii (Leguminosae). J Parasitol 88: 163-170. 
Mahmoud MR, El-Abhar HS, Saleh S 2002. The effect of Nigella sativa oil against the liver damage induced by Schistosoma mansoni infection in mice. J Ethnopharmacol 79: 1-11.

Maizels RM, Bundy DA, Selkirk ME, Smith DF, Anderson RM 1993. Immunological modulation and evasion by helminth parasites in human populations. Nature 365: 797-805.

Mansour JM, Mccrossan MV, Bickle QD, Mansour TE 2000. Schistosoma mansoni phosphofructokinase: immuno-localization in the tegument and immunogenicity. Parasitology 120: 501-511.

Mansour SA, Ibrahim AM, Abdel-Hamid HF 2002. Botanical Biocides 8. Impact of some plant extracts on Biomphalaria alexandrina snails and on Schistosoma mansoni miracidia and cercariae. Egypt J Schistosomiasis Infect Endem Dis 24: 81-94.

Mckee T, Mckee JR 1999. In AK Peterson, MB Horn (eds), Biochemistry: an Introduction, McGraw-Hill, New York, p. 322-330.

Mclaren D 1980. Schistosoma manson. In NK Brown, The Parasite Surface in Relation to Host Immunity, John Wiley, England, New York, p. 1-27.

Mei H, LoVerde PT 1995. Schistosoma mansoni: cloning the gene encoding glutathione peroxidase. Exp Parasitol 80: 319-322.

Mei H, LoVerde PT 1997. Schistosoma manasoni: the developmental regulation and immunolocalization of antioxidants. Exp Parasitol 86: 69-78.

Mei H, Thakur A, Schwartz J, LoVerde PT 1996. Expression and characterization of glutathione peroxidase activity in the human blood fluke, Schistosoma mansoni. Infect Immun 64: 4299-4306.

Mkoji GM, Smith JM, Prichard RK 1988a. Antioxidant systems in Schistosoma mansoni. Correlation between susceptibility to oxidant killing and the levels of scavengers of hydrogen peroxide and oxygen free radicals. Int J Parasitol 18: 661-666.

Mkoji GM, Smith JM, Prichard RK 1988b. Antioxidant systems in Schistosoma mansoni: Evidence for their role in protection of the adult worms against oxidant killing. Int J Parasitol 18: 667-673.

Mkoji GM Smith, JM Prichard RK 1989. Glutathione redox state, lipid peroxide evels and activities of glutathione enzymes in oltipraz-treated adult Schistosoma mansoni. Biochem Pharmacol 38: 4307-4313.

Moczon T, Swiderski Z 1983. Schistosoma hematobium: oxidoreductase histochemistry and ultrastructure of niridazole treated females. Int J Parasitol 13: 225-232.

Molgaard P, Nielsen SB, Rasmussen DE, Drummond RB, Makaza N, Andreassen J 2001. Anthelmintic screening of Zimbabwean plants traditionally used against schistosomiasis. J Ethnopharmacol 74: 257-264.

Nagi MN, Alam K Badary OA, Al-Sawaf HA, Al-Bekairy AM 1999. Thymoquinone protects against carbon tetrachloride hepatotoxicity in mice via an antioxidant mechanism. Biochem Mol Biol Int 47: 153-159.

Naples JM, Shiff CJJ, Rosler KH 1992. Schistosoma mansoni: Cercaricidal effects of cedarwood oil and various of its components. Am J Trop Med Hyg 95: 390-396.
Nare B, Smith JM, Prichard RK 1990. Schistosoma mansoni: levels of antioxidants and resistance to oxidants increase during development. Exp Parasitol 70: 389-397.

Nare B, Smith JM, Prichard RK 1991. Differential effects of oltipraz and its oxy-analogue on the viability of Schistosoma mansoni and the activity of glutathione-s-transferase. Biochem Pharmacol 42: 1287-1292.

Ndamba J, Nyazema N, Makaza N, Anderson C, Kaondera $\mathrm{KC}, 1994$. Traditional herbal remedies used for the treatment of urinary schistosomiasis in Zimbabwe. J Ethnopharmacol 42: 125-132.

Nosseir M, Metwally A, Kamel G, Guirguis F, Nessim N 2000. Evaluation of the effect of RO 15-5458 and combined antischistosomal drugs on different strains of Schistosoma mansoni infected albino mice: Histopathological and parasitological study. Egypt J Schistosomiasis Infect Endem Dis 22: 115-136.

O'Leary KA, Tracy JW 1991. Schistosoma mansoni: glutathione S-transferase-catalyzed detoxication fo dichlorvos. Exp Parasitol 72: 355-361.

O'Leary KA, Hathaway KM, Tracy JW 1992. Schistosoma mansoni: Single-step purification and characterization of gutathione 5-transferase isoenzyme 4. Exp Parasitol 75: 47-55.

Olivier L, Stirewalt, MA 1952: An efficient method for exposure of mice to cercariae of S. mansoni. J Parasitol 38: 1923.

Otubanjo OA 1981. Schistosoma mansoni. Astiban-induced damage to tegument and the male reproductive system. Exp Parasitol 52: 161.

Paglia DE, Valentine WN 1967. Studies on the quantitative and qualitative characterization of erythrocyte glutathione peroxidase. J Lab Clin Med 70: 158-169.

Paoletti F, Aldinucci D, Mocali A, Caparrini A 1986. A sensitive spectrophotometric method for the determination of superoxide dismutase activity in tissue extracts. Anal Biochem 154: 536-541.

Pellegrino J, DeMaria M 1966. In vitro cercaricidal activity of schistosomiasis. J Parasitol 52: 617.

Ritchie LS, Lopez VA, Cola JM 1974. Prolonged application of an organation against Biomphalaria glabrata and Schistosoma mansoni. In C Tomas, Molluscicides in Schistosomiasis Control, Academic Press, New York, London, p. 77-88.

Roche C, Liu JL, LePresle T, Capron A, Pierce RJ 1996. Tissue localization and stage-specific expression of the phospholipid hydroperoxide glutathione peroxidase of Schistosoma mansoni. Mol Biochem Parasitol 75: 187-195.

Sharma R, Agarwal A 1996. Role of reactive oxygen species in mal infertility. Urology 48: 835-850.

Shengliang Y, Coles GC, Doenhoff MJ, Southgate VR 2001. In vitro responses of praziquantel-resistant and-susceptible Schisotosma mansoni to praziquantel. Int J Parasitol 31: 1227-1235.

Smith JM, Mkoji GM, Prichard PK 1989. Depression of hydrogen peroxide dependent killing of schistosomula in vitro by peritoneal exudate cells from schistosoma mansoni infected mice. Am J Trop Med Hyg 40: 186-194. 
Smithers SE, Terry RJ 1963. The infection of laboratory hosts with cercariae of Schistosoma mansoni and the recovery of worms. Parasitology 55: 595-600.

Smithers SR, Terry RJ 1969. Immunity in schistosomiasis. Ann NY Acad Sci 160: 826-940.

Sparg SG, Van Staden J, Jager AK 2000. Efficiency of traditionally used South African plants against schistosomiasis. J Ethnopharmacol 73: 209-214.

Stocchi V, Biagiarelli B, Fiorani M, Palma F, Piccoli G, Cucchiarini L, Dacha M 1994. Inactivation of rabbit red blood cell hexokinase activity promoted in vitro by an oxygen-radical-generating system. Arch Biochem Biophys 311: 160-167.

Technounwou PB, Englande AJ, Malek EA, Anderson AC, Abdel-Ghany AA 1991. The effects of Bayluscide and Malathion on miracidial survival in schistosomiasis control. J Environ Sci Hlth 26: 69.

Tielens AGM, Houweling M, VanDen Bergh SG 1985. The effect of 5-thioglucose on the energy metabolism of Schistosoma mansoni in vitro. Biochem Pharmacol 34: 33693373.

Uyeda K, Racker E 1965. Regulatory mechanism in carbohydrate metabolism VII Hexokinase and phosphofructokinase. J Biol Chem 240: 4682-4688.
WHO 1993. The control of schistosomiasis: second report of the WHO expert committee. WHO Technical Report Series 830 , Geneva.

WHO 1999. Report of the WHO informal consulation on schistosomiasis control. WHO/CDS/CPC/SIP/99,2, Geneva.

Xiao SH, Hotez PJ, Tanner M 2000. Artmether, an effective new agent for chemoprophylaxis against schistosomiasis in China: its in vivo effect on the biochemical metabolism of the Asian schistosome. Southest Asian J Trop Med Pub Health 31: 724-732.

Xiao SH, You JQ, Guo HF, Jiao PY, Mei JY, Yao M, Feng Z 1998a. Effect of artemether on glyceraldehyde-3-phosphate dehydrogenase, phosphoglycerate kinase and pyruvate kinase of Schistosoma japonicum harbored in mice. Acta Pharmacol Sinica 19: 279-281.

Xiao SH, You JQ, Guo HF, Jiao PY, Mei JY, Yao MY, Feng Z 1998b. Effect of artemether on hexokinase, glucose phosphate isomerase and phosphofructokinase of Schistosoma japonicum harbored in mice. Chinese J Parasitol Parasit Dis 16: 25-28.

Xiao SH, You JQ, Guo HF, Mei JY, Jias Chollet J, Tanner M, Utzinger J 2002. Schistosoma japonicum: effect of artemether on glutathione s-transferase and superoxide dismutase. Exp Parasitol 102: 38-45. 
